\title{
Acesso ao Ensino Superior: Uma Visão*
}

\author{
(Menos que uma versão preliminar)
}

Sergio Costa Ribelro**

\section{INTRODUÇĀO}

Tradicionalmente, o acesso ao ensino superior no Brasil tem sido tratado como "Demanda à Universidade", isto é, do ponto de vista dos interesses da Universidade 1 .

A evoluçáo do processo de acesso tem mostrado nos últimos anos que o modelo de Vestibular vem refletindo uma visâo da funçăo social do ensino superior cada vez mais distanciada da realidade e das necessidades de um pafs que se pretende modernizar $\mathrm{e}$, por sua vez, reflete um modelo de sociedade que contextualiza essa visäo.

Num país com as disparidades educacionais como o nosso, as funçöes do sistema de ensino superior se diferencia bastante de seus congêneres do primeiro mundo e pode não só estar desfocado, como representar um sistema de privilégios medievalescos do uma classe neo-aristocrática urbana c uma caricatura de uma universidade moderna.

No primeiro mundo, sem querer indicar uma direçäo de causalidade, a educação básica foi universalizada nos últimos dois séculos. O progresso tecnológico após a segunda grande guerra tem indicado o caminho, irreversfvel, da internacionalizaçáo do capital e da clivagem entre importadores e exportadores de tecnologias. Os blocos supra nacionais que se estruturam formam-se acima de nacionalismos culturais e ideologicos $\mathrm{e}$ visam a atingir mercados terceiro mundistas de forma cada vez mais agressiva.

Neste contexto internacional, um modelo de sociedade baseado numa pequena elite esclarecida c numa massa de semi-escravos năo educados está fadado ao completo fracasso.

- Oautor agradece as frutfferas discussöes sobre o assunto com Nelson do Valle e Silva e Philip R. Fletcher, mas assume total responsabilidade pelos erros emítidos.

-. Do Laboratório Nacional de Ciencias da Computaşa (LNCC) e do CNPq.

1 Ostermos Universidade, Faculdade e Ensino Superior seråo utilizados, neste artigo, de forma equivalente e podem significar qualquer tipo de edueaç̆o formal pós-secundária. 
Não creio que estaremos exagerando ao comparar este modelo ao de uma sociedade de índios que se organiza, com sucesso, a partir de competências de arco e flexa e de uma cultura agrícola rudimentar sendo invadida por uma sociedade mais avançada (lemos isto todos os dias nos jornais). As politicas protecionistas (reservas indígenas?) năo parecem estar produrindo os efeitos esperados!

Năo se trata aqui de ressuscitar ideologias (teorias?) questionáveis de capital humano ou de segmentaçäo de mercado e sim reconhecer que cada atividade produtiva está inscrida numa escala de prestígio extremamente estável e histórica e culturalmente determinada e, por conseguinte, de diffcil alteraçắo. No entanto, uma idéia pode ser discutida como a elaborada por Thurow ${ }^{2}$, onde o recrutamento para as diversas atividades se dá em "balcōes", onde se formam filas e a escolha 6 feita a partir da competência especfifica do candidato e nấo a partir de indicadores cartoriais, por exemplo, de educaçăo formal.

É claro que tercmos que superar o nepotismo, o clientelismo medieval e o corporativismo mal direcionado.

A partir do aumento da competência especifica de todos os indivíduos da sociedade poderfamos caminhar em direção a uma sociedade mais competitiva capaz de enfrentar com competência o avanço inexorável da internacionalizaçăoda economia e absorver, $5 \mathrm{~cm}$ destruiçäo de sua própria cultura, as competências necessárias às novas realidades tecno16 gicas e sociais.

A própria noçäo de Estado e de Cidadania tem a ver com uma inculcação ideológica, qualquer que seja ela (Democracia, por exemplo), realizada pela escola.

É possivel ainda imaginar que tal politica venha, a longo prazo, diminuir as disparidades de renda onde, hoje, o Brasil é o campeấo mundial. A alternativa do isolamento internacional parece-nos uma soluçăo completamente inviável no mundo atual.

E nessa linha de raciocfnio que gostarfamos de analisar alguns dados factuais $\mathrm{c}$ propor algumas reflexöes.

\section{$O$ ACESSO AO $2^{\circ}$ GRAU}

É extremamente diffcil analisar as condiçöes de acesso ao ensino superior sem avaliar corretamente o que se passa nos graus anteriores de ensino.

A seleção (ou cxclusão) no sistema de ensino básico formal da populaçăo brasileira e de tal ordem que inviabiliza qualquer idćia de soluçāo emergencial do problema. Sabemos hoje que $90 \%$ de uma coorte de idade ${ }^{3}$ ingressa na $1^{9}$ Série do Primciro Grau. A cvolução desta geraçăo através deste Grau de ensino, devido às fantásticas taxas de repetência e posterior evasāo (ou exclusäo) do sistema, produz como resultado uma proporçäo de apenas $38 \%$ de graduados, a partir daf pouco mais de $20 \%$ ingressa na $1^{\mathrm{a}}$ Série do Segundo Grau".

2 Thurow, L (1975), Generating Inequality, Basic Books.

3 Uma coorte de idade correspondente ao número de pessoas, na populaçăo, com a mesma idade e representa uma geraçăo, tsto $E$, o número de indiviđuos que, a cada ano, deveria entrar no sistema de casino.

4 O Mérica, por exemplo, com uma renda média per copita muito próxima à nossa, e uma distribuiça đe renda também parccide, consegue graduar cerca de $60 \%$ de uma coorte. 
A distribuiçāo destes $20 \%$ pelos percentis de renda familiar per capita da populaçăo é extremamente perversa como mostra a Figura 1.

\section{FIGURA 1}

\section{ACESSO AO $2^{\circ}$ GRAU \\ SUDESTE URBANO}

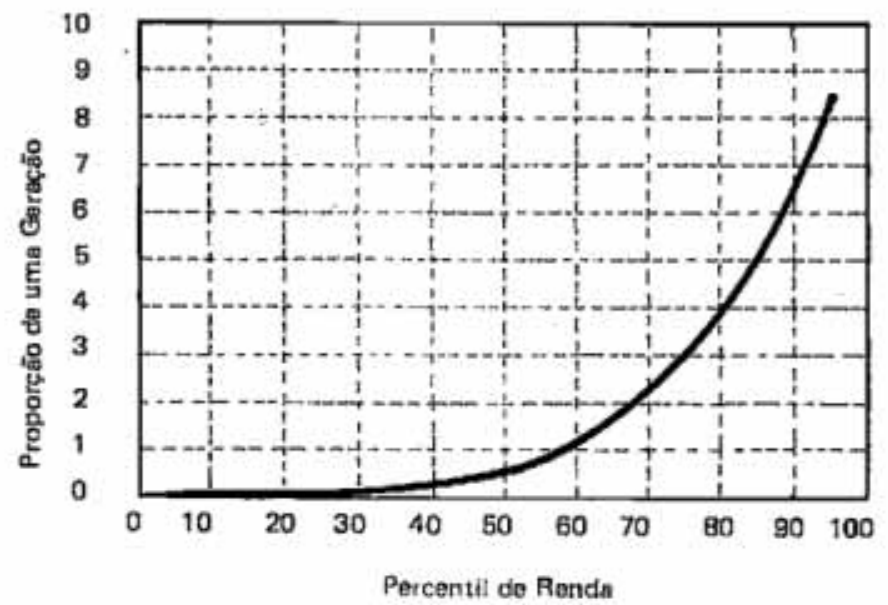

Fonte: Modelo PROIZUXO aplicado a đados da PNAD $82^{5}$

Vcmos que, praticamente, só têm acesso ao $2^{\natural}$ Grau indivíduos com renda acima do sexagésimo percentil, mesmo na regiāo mais desenvolvida do pafs, o sudeste urbano.

É nesta situaçăo que nos perguntamos:

- Por que a variância no domfnio cognitivo desses $40 \%$ mais "ricos" é tão alta c está aumentado como "parece" estar indicando os exames vestibulares das últimas décadas?

- Será possível modernizar o Brasil, dentro dos conceitos emitidos acima, com este perfil educacional?

- Qual o papel da universidade numa sociedade como esta?

Em relaçâo a primeira pergunta alguns dados adicionais tornam ainda mais perversa a situaçio. A Figura 2 mostra como as diversas carreiras na universidade sofrem uma forte pré-seleçäo sócio-cultural no seu processo de escollha e quẩo díspare é o desempenho médio de seus "eleitos".

5 "Modeling Education System Performance with Demographic Data - An Introduction to the Profluxo Model", Philip R. Fieteher e S. Costa Ríbeiro, 1989 (mimeo)

6 Ver "Vestibular88, Seleçâo ou Exclustı?", S. Costa Ribeiro, Educaçāo e Seleção, nº 18, jul/dez 1988, p.93. 


\section{FIGURA 2}

VESTIBULAR 1979

DEPENDÊNCIA DO DESEMPENHO PELO NIVEL SOCCIO-CULTURAL

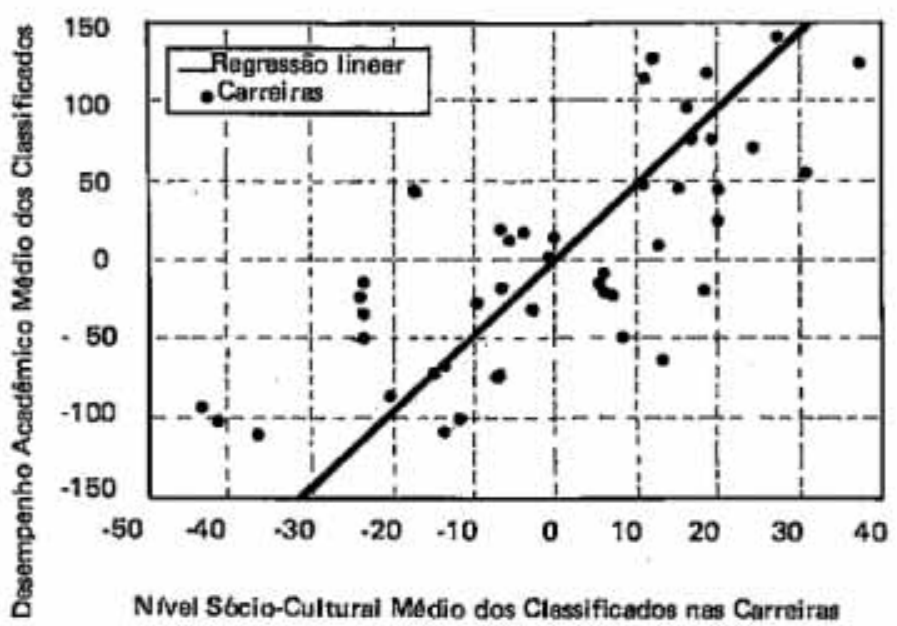

Como consequência desta variância de desempenho e das políticas de acesso praticadas nos vestibulares das universidades públicas nos último anos chegamos à situaçāo de deixar as vagas destinadas às carreiras que levam ao magistério de $2^{\circ} \mathrm{Gran} \mathrm{em}$ grande parte ociosas, como mostra a Figura 3.

As universidades públicas estāo definindo, assim, uma politica clara de abandono de suas responsabilidades na formaçäo de docentes para os graus anteriores de ensino.

Uma conta simples mostra o que nos reserva of futuro da qualidades docente do $2^{\circ}$ Grau. No caso do ensino de Física ( 3 anos de curso), por exemplo, s6 para manter a atual situaçăo, isto $6,20 \%$ de uma geraçäo no $2^{\circ}$ Grau, terfamos que formar por ano o seguinte número de licenciados competentes:

$$
\mathrm{N}=\frac{0,2 \times C_{i} \times 3 \text { (anos) }}{N_{\text {ap }} \times V_{\text {mp }}}
$$

Onde: $\quad \mathrm{C}_{1}=\mathrm{O}$ valor de uma coorte de idade $\approx 3 \times 10^{6}$ indivfduos, no pals $\mathrm{n}_{\text {ap }}=$ número de alunos por professor por ano $\approx 90$ (recomendaçăo da UNESCO) 
FLGLRA 3

VESTIBCLAR 19R6; FHIERAIS DO GRANDE RIO DEPLNDÉNCIA DO PRLENCIIIMEXTO DAS YAGAS PELO NFYL SOCTUCUITLRAL

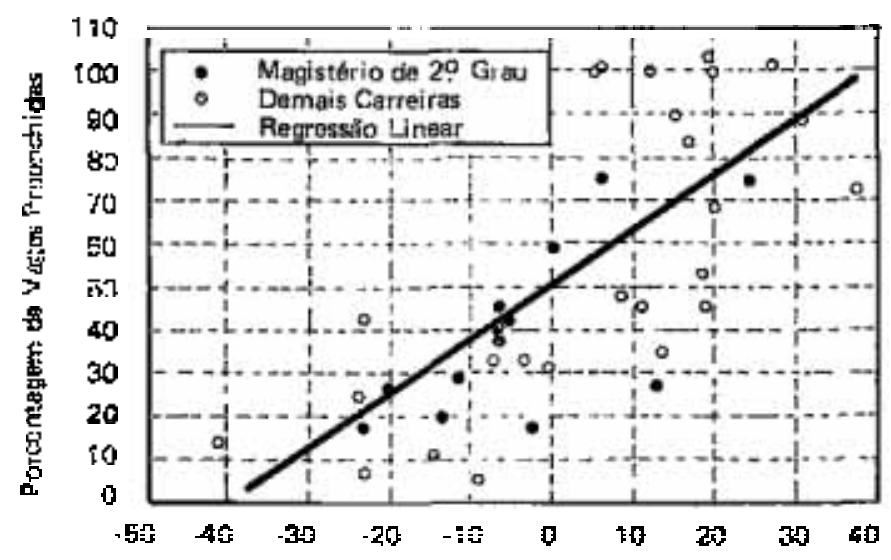

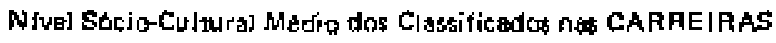

Sbs. Fiste número 6 ainda uma fantasial, no infeio da decenda de oitenta, no Estado do Ric id Jantito, era $4121^{7}$

$\mathrm{V}_{\mathrm{mp}}=$ vida media de atividade de um professor $\approx 25$ anos

Wm tsies dados $\mathrm{N}=500$ por $a n$, caso assumirmos que pắo haja menhuma "mort jiade" durante a vida prolissional desses professotes.

Westno com esse nóncro extremamenle conservador, nos perguntamos:

- Oude e corno estão sendo formados estes prolissionais?

Comp levar em copla que a cobertura do sistema de tentino de $2^{2}$ Grau esta

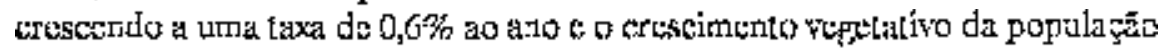
de $1,5 \%$ an ano na fajxa de renda cortesporstente?

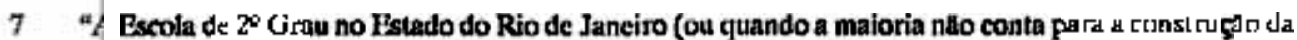

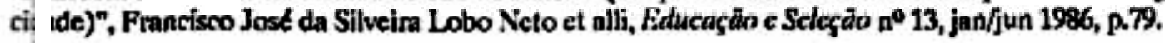




\section{FIGURA 4}

TAXAS DE PARTICIPAÇÃo NA EDUCAÇÃo BRASILEIRA, POR SÉRIE

\section{E POR PERCENTIL DE RENDA}

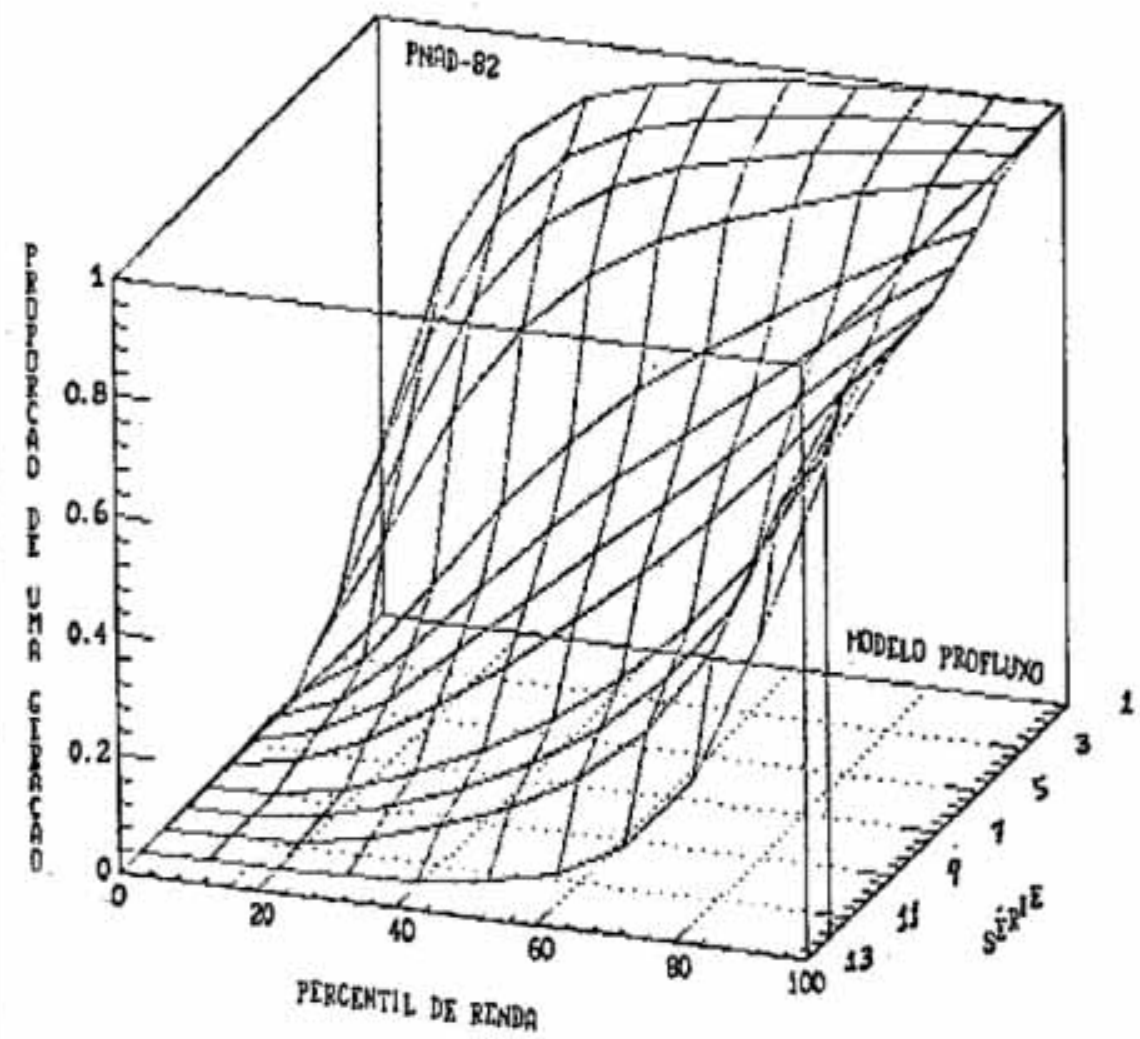

Fonte: Modelo PROFLUXO aplicado a dados da PNAD $82^{8}$

Há que considerar, ainda, a queda observada nos últimos anos das taxas de fecundidade no Brasil (a maior queda observada, em qualquer paifs, em toda a história da humanidade). Esta queda irá provocar um envelhecimento da populaçăo, que, associada ao aumento da cobertura do sistema educacional na população, demandará um incremento do estoque de professores com titulaçäo mais alta.

Op. cit. ref. 5 


\section{Das Difienldades de Universalizaçăo da Educaçáo Báslea}

A Figura 4 mostra, para o Brasil como um todo, as taxas de participaçāo no sistema educacional da $1^{\mathrm{a}}$ Série do $1^{\circ} \mathrm{Grau}$ até a $1^{\mathrm{t}}$ Sćric da universidade (a $12^{\mathrm{a}}$ Série).

Vemos que o acesso ao $1^{\text {9 }}$ Grau está praticamente universalizado a partir do vigésimo percentil de renda, abaixo deste estão os habitantes das regiōes mais pobres do pafs, representada em cerca de $70 \%$ pelo nordeste rural pobre (14\% da população nacional). Nestas regióes, a melhoria das condiçōes e da qualidade da educaçäo requer professores qualificados com perfis de renda compativel, af reside a primeira grande dificuldade. Como aceitar que seja possivel a profissionais que só são formados, em números significativos ( $2^{\circledR}$ grau), a partir do $45^{\circ}$ percentil de renda possam entrar na fila para ocupar os poslos docentes nessas regiōes? Esta 6 uma transição socialmente proibida.

Algo inteiramente análogo ocorre entre a $4^{n}$ e a $5^{n}$ séries do $1^{\circ} \mathrm{Grau}$. É em torno do $40^{\circ}$ percentil de renda que vamos observar a maior elasticidade do sistema, isto $\hat{E}$, nesta faixa de renda que obteríamos o mais rápido incremento nas taxas de participaçăo caso injetássemos recursos financeiros e humanos, porém, para isto, precisamos de docentes com nível superior, o que $s 6$ vamos encontrar a partir do $70^{\circ}$ percentil, novamente aqui ninguém entraria nesta fila! $O$ mesmo raciocínio pode ser feito em relaçăo ao $2^{\circ} \mathrm{Grau}$.

É assim que se forma, no senso comum, a idcia de que o aumento do número de alunos baixa a qualidade do ensino! Esta fila ć formada por individuos sem as competências necessárias.

É impossivel melhorar a qualidade dos graus anteriores de ensino sem uma politica nacional de valorizaçäo da carrcira de magistério concomitantemente aumento da competência especifica destes profissionais.

A polfitica recém desmascarada pelo vestibular dos áltimos anos mostra como a universidade páblica brasileira está completamente alienada em relaçăo a estes problemas, envolvida que está num corporativismo sindical (leia-se trabalhar menos e ganhar mais). A farsa da indissociabilidade entre ensino c pesquisa (hoje grafada na constituiçăo) c lida a nível individual e näo institucional como deveria ser feita. Deixa-se a formaçâo dos docentes dos graus básicos de ensino às faculdades de periferia de reconhecida baixa qualidade.

É claro que a pesquisa de ponta, básica e aplicada, é importante e essencial na universidade, mas scrá que esta atividade é, neste momento histórico internacional, mais importante que a universalizaçảo compctente da educaçäo básica?

Outro dado de máxima relevância neste contexto diz respeito a um indicador importante para uma naçấo que deseja se modernizar: o percentual da populaçảo de $20 \mathrm{a}$ 24 anos matriculada no ensino superior. Enquanto nos EEUU e Canadá esta percentagem é da ordem de $60 \%$, na Europa ocidental de $45 \%$ e na América do Sul de $15,5 \%$ e crescendo. No Brasil atingimos $11 \%$ no final da década passada. Hoje este percentual está caindo situando-se um pouco acima de $9 \%$.

Diante das análises rascunhadas acima acreditamos que, mantidas as atuais polfticas na universidade brasileira, a situaçäo da educaçāo básica vai deteriorar-se cada vez mais, com graves reflexos para o futuro da propria "universidade de ensino e pesquisa", tăo "protegida" em seu feudo corporativo pela nova Constituiçăo. 